\title{
REPUBLICANISMO Y POSMODERNISMO EN LOS NUEVOS MOVIMIENTOS SOCIALES Una aproximación a los indignados
}

\author{
REPUBLICANISM AND POSTMODERNISM IN NEW SOCIAL MOVEMENTS \\ An approach to the indignados movement
}

\author{
María Ángeles Abellán López \\ Universidad Miguel Hernández, España, ma.abellan@umh.es
}

Recibido: 14 de abril, 2015 Aceptado: 24 de noviembre, 2015

\begin{abstract}
Resumen: Esteartículo pretendeexploraralgunos vínculos teóricos entreel republicanismo contemporáneo y los movimientos sociales, con una aproximación posmoderna, en la búsqueda de mayor participación, de la regeneración democrática y de la innovación política, a través de la centralidad del espacio público como un locus político. A partir del estudio del movimiento de indignados se abordarán las principales reivindicaciones políticas orientadas a profundizar la democracia y asumir valores cívicos republicanos.
\end{abstract}

Palabras clave: Participación, movimientos sociales, ciudadanía, republicanismo, democracia, postmodernismo.

\begin{abstract}
This paper explores some theoretical links between contemporary republicanism and social movements, with a postmodern approach, in a search for greater participation, democratic regeneration and political innovation through the centrality of public spaces as a political locus. Using the indignados movement, the main political demands aimed at deepening democracy and assuming republican civic values will be addressed in this paper.
\end{abstract}

Keywords: Participation, social movements, citizenship, republicanism, democracy, postmodernism.

\section{Planteamiento general}

Los Nuevos Movimientos Sociales (NMS) son considerados como vehículo de la expresión participativa que buscan ensanchar la praxis política y para ello trascienden el marco estrictamente demoliberal, de modo que se orientan hacia un paradigma más horizontal e inclusivo como el que suministra el neorrepublicanismo'. Estos actores colectivos se caracterizan por su capacidad para politizar los diferentes asuntos, lo que los convierte en una eficaz caja de resonancia. La movilización de estos grupos abiertamente a favor de un modelo de democracia más interactiva, reivindican el autogobierno

$1 \quad$ Con este término se hace referencia al revisionismo experimentado por el republicanismo contemporáneo tras incorporar algunas adaptaciones liberales, como los derechos y libertades individuales, el pluralismo y el rechazo de una concepción sustantiva del bien (como la que sostienen algunos comunitaristas). 
y la necesidad de una constante vigilancia sobre los poderes públicos como medida de control. Este artículo pretende explorar algunos vínculos teóricos entre el republicanismo contemporáneo y los movimientos sociales desde un enfoque posmodernista. La búsqueda de mayor participación y de regeneración democrática es pensada y realizada desde la centralidad que otorga el espacio público. A partir del estudio del movimiento de indignados se abordarán las principales reivindicaciones políticas orientadas a profundizar la democracia y asumir valores cívicos republicanos. El presente trabajo se ha elaborado desde un enfoque teórico normativo, pero ha incorporado elementos de la observación empírica de movimientos sociales concretos, que se han desarrollado en nuestro contexto, como el de los indignados. Se han utilizado fuentes secundarias citadas en las referencias, partir de las cuales se han elaborado algunos de los argumentos que considera este artículo.

\section{Los movimientos sociales en las democracias contemporáneas}

Uno de los actores sociales y políticos con más protagonismo mediático en la vida colectiva son los nuevos movimientos sociales, que se han convertido en agentes de cambio y de transformación democrática. Las protestas y la contestabilidad social forman parte de sus señas de identidad unido a su liderazgo característico para enfrentar los nuevos problemas que emergen en la sociedad del siglo XXI, en la que los partidos y sindicatos tradicionales se ven incapaces de solucionar, y a veces, sobrepasados por los acontecimientos del espacio público.

Estas modalidades colectivas de participación se han ido abriendo paso y han ganado un espacio que ocupaban los actores políticos convencionales, de forma, que han devenido en una fuerza social que representa una democracia más plural, abierta y participativa que puede mejorar la calidad democrática (Ibarra, Martí y Gomà, 2002; Dalton y Kuechler, 1992).

El calificativo nuevo, sugiere que la supuesta novedad de tales movimientos es para diferenciarlos de los antiguos movimientos de finales siglo XIX y principios del XX (Kaase, 1992, p. 125, citado en; Dalton y Kuechler, 1992). Los viejos movimientos sociales como las movilizaciones de los campesinos, de los obreros industriales y movimientos contra el racismo, suelen destacar la base clasista del conflicto, en la medida en que tales movimientos se sustentaban sobre la combinación de intereses económicos y redes sociales claramente definidas. Por lo siguiente, los movimientos representan intereses de un segmento social muy específico y dependían de las redes organizativas que integraban el colectivo de clase (Dalton, Kuechler y Bürklin, 1992, p. 31, en Dalton y Kuechler). No obstante, esta visión clasista parece insuficiente para dar cuenta de la complejidad del fenómeno. Los NMS presentan una serie de atributos singulares que los diferencian de los viejos movimientos, puesto que no se dirigen a ningún grupo social específco y la extracción de su base social no pertenece a colectivos desfavorecidos o en situaciones precarias necesariamente. Los apoyos que reciben se caracterizan por la transversalidad y, superan las divisiones basadas en el sexo, edad o nivel cultural, pues el vínculo movilizador son las ideas y los valores.

La conceptualización de los NMS resulta una tarea compleja debido a sus dificultades para establecer una definición aceptada con unanimidad, por lo que una opción aceptable para abordar 
su delimitación conceptual sea establecer algunos de sus elementos definitorios como: a) se integran en un paradigma particular de las formas de vida moderna, b) comparten un acervo común de valores posmaterialistas, c) entretejen una red de redes $y, d$ ) carecen de ideología coherente, pero detentan una multiplicidad temática, e) tienen una débil estructura organizativa, recurren a la acción directa y su orientación es internacional (Kaase, 1992, citado en Dalton y Kuechler, 1992).

Una conceptualización más dinámica del fenómeno de los movimientos sociales la encontramos en Tarrow (2012) que afirma que el acto irreductible que subyace en todos los movimientos sociales es la acción colectiva contenciosa y se convierte en tal, cuando es utilizada por los ciudadanos, que carecen de acceso regular a las instituciones, actúan en nombre de reivindicaciones nuevas o no aceptadas, y se conducen de un modo que constituye una amenaza fundamental para otros o para las autoridades. Esta acción política colectiva surge cuando se dan las oportunidades políticas para la intervención de actores sociales que carecen de estas, se apoya en marcos culturales y repertorios, introducen innovaciones en los márgenes, a través de los cuales se estructura la acción social y conduce a una interacción sostenida contra sus oponentes.

El paso de la acción colectiva a la cristalización en movimiento social es unos de los momentos más importantes del proceso movilizador porque, además de aprovechar las oportunidades políticas que se presentan en una determinada coyuntura, se fraguan redes sociales y estructuras de conectividad que crean marcos cognitivos y discursivos que, a su vez, generan identidades de apoyo. ¿Necesitan las democracias contemporáneas de estas formas participativas como son los movimientos sociales?

Eder (1998, p. 344, citado en Ibarra y Tejerina) sostiene que la misma sociedad moderna ha cambiado el papel de los movimientos y ha creado espacios de acción social para movimientos que no existían anteriormente. Esta afirmación es fundamental para comprender que los movimientos han dejado de ser percibidos como desestabilizadores y son asumidos como agentes en un escenario en transformación constante. Si bien la capacidad de los movimientos sociales para realizar sus objetivos generales ha sido baja, sí son eficaces a la hora de trasladar nuevas cuestiones al debate público en la tematización de los repertorios (Della Porta y Diani, 2011, p. 294).

El impacto de los movimientos sociales ha conseguido posicionar en el espacio público y en la discusión política temas heterogéneos que responden a la diversidad de las sociedades del siglo XXI. El medioambiente, la cuestión de género, los problemas de identidad cultura y étnica, el acceso a la vivienda, la educación, la ayuda al desarrollo, el patrimonio cultural, los derechos de los animales, el pacifismo, la inquietud por las consecuencias de la globalización capitalista, entre otros muchos, han centrado la atención de los movimientos sociales, y han conseguido difundirla al resto de la sociedad. Muchos de los grandes valores sustanciados en estas preocupaciones sociales son conocidos como posmaterialistas (Inglehart, 1991), en oposición a los materialistas, y se refieren a aspectos intangibles relacionados con el estilo y a la calidad de vida que defienden estos movimientos. 
Los movimientos por la solidaridad, movimientos bajo el lema "Salvemos...", el movimiento de los indignados, las mareas de colores, las plataformas anti desahucios incluyen contenidos de emancipación política que, desde un enfoque posmaterialista, reivindican valores materialistas. Si bien muchos de estos movimientos se caracterizan por sus contenidos reivindicativos dentro del marco dibujado por la globalización, es incuestionable que los contextos locales y las estrategias nacionales influyen en los repertorios sustantivos y de acción de los movimientos sociales y, como sostiene Tarrow (2012, p. 443) a pesar de la globalización, las sociedades no responden en bloque ante los mismos estímulos.

Una de las señas de identidad de los NMS es su defensa de un paradigma social más horizontal y comprensivo, que facilite mayores oportunidades para participar en las decisiones públicas; en este artículo se considera que una lectura desde el discurso neorrepublicano contribuye a una mejor comprensión de los movimientos sociales en sus críticas al sistema representativo y sus propuestas de mejora democrática.

\section{El pensamiento republicano en los NMS: un enfoque posmoderno}

El universo de los conflictos políticos sigue existiendo y también el mundo de las resistencias. El pluralismo teórico que nutre los NMS es un pluralismo de orientaciones sin que exista un estilo hegemónico, y ello permite la coexistencia de tendencias contrapuestas. En teoría política no hay un paradigma superado de una vez por todas porque, cuando se considera superado una teoría, esta puede experimentar un renacimiento como demuestran los numerosos neo movimientos (Von Beyne, 1994, p. 320). Al seguir esta línea argumental, en los NMS se concitan una pluralidad de ideas que se combinan según los diferentes contextos. Los dos bloques de desarrollos sobre los que abordamos la fundamentación teórica de los NMS son el republicanismo y el postmodernismo. Asimismo, dada la consistencia del republicanismo como una de las matrices de la democracia liberal y con una dilatada trayectoria histórica, le dedicaremos una atención preferente.

El republicanismo es una vieja tradición que asociamos a clásicos como Cicerón, Maquiavelo o Rousseau, ha resurgido con fuerza en la teoría política actual. La tradición republicana² representa una de las teorías políticas actuales que mejor sistematiza los déficits cívicos contemporáneos y reivindica la centralidad del espacio público como un locus necesario de deliberación (Abellán, 2014, p. 199). La realización humana solo es posible cuando se actúa dentro de una comunidad política libre y con autogobierno. Arendt (1997) consideraba la política como un transcendental del hombre, que responde a un fundamento ontológico, porque los seres humanos necesitan el espacio público para representarse, para darse a conocer y auto expresarse; es su apertura al

$2 \quad$ El republicanismo es una vieja tradición cuyas raíces pueden rastrearse en un dilatado horizonte temporal, pero es en el siglo pasado cuando ha resurgido con fuerza en el mundo anglosajón de la mano de autores de la talla como Hannah Arendt, J.A.G. Pocock, Quentin Skinner, Philipp Pettit, Maurizio Viroli, y ha transmitido su renovado influjo a la teoría política actual. Por consiguiente, caracterizaremos de modo genérico las bases del republicanismo sin intentar delimitar todos los significados que histórica y políticamente se le han ido atribuyendo ni elaborar una tipología mínima siquiera. 
mundo. Este reconocimiento de la dimensión política es uno de los rasgos más destacados del discurso republicano, que aparece con renovada energía en el panorama político, y con vocación de servir de guía para revitalizar la democracia contemporánea. La emergencia de reivindicaciones que propugnan la recuperación del espacio político como núcleo central cohesivo, la participación ciudadana en la cosa pública, el giro deliberativo en los procedimientos democráticos y en la toma de decisiones se ha posicionado en el debate democrático contemporáneo.

La democracia liberal desincentiva la participación política activa porque no necesita ciudadanos virtuosos y alienta que los individuos se dediquen a sus actividades privadas, que persigan el disfrute de sus derechos y que las tareas de acción y gestión política sean asumidas por políticos profesionales. Se argumenta que la complejidad de nuestras sociedades hace imposible la deliberación y se tiende a sustituir la participación y el debate por una política tecnocrática, basada en el poder de los especialistas. Precisamente, en un momento de desprestigio de la política y de insatisfacción ciudadana con el modelo democrático liberal representativo, el republicanismo cívico sirve de inspiración para revitalizar la democracia contemporánea.

En esta línea de recuperación de lo público, la tradición republicana ha emergido vigorosa y reclama una reconsideración del papel del ciudadano, su compromiso con las instituciones políticas y el cumplimiento de sus deberes cívicos para con su comunidad rasgos presentes en el republicanismo de Maquiavelo donde la valoración de la ciudadanía, la deliberación para el autogobierno y la consideración positiva de lo público aportan plenitud al concepto de democracia (Abellán, 2014).

El discurso republicano contribuye al debate sobre la calidad democrática al enfatizar aspectos fundamentales como la valoración del papel del ciudadano, el compromiso participativo, el reconocimiento de las instituciones, la deliberación, el autogobierno y la centralidad del espacio público. De este modo, la contribución del republicanismo con su defensa de una ciudadanía más activa, participativa, vigilante y comprometida con el interés general, ha encontrado un terreno fértil en los movimientos sociales. Uno de los presupuestos republicanos es que todos los individuos cuentan porque la comunidad política requiere tratar a todos como iguales. La tradición republicana concibe la libertad como no dominación (Pettit, 1999) y es diferente a la libertad liberal como no interferencia porque, formalmente, se pueden disponer de derechos fundamentales pero, materialmente, se puede estar condicionado por relaciones de dominación económica, sexual o patriarcado, que impiden el ejercicio real de tales libertades y derechos individuales. Una importante contribución neorrepublicana es que la libertad individual es inseparable de la libertad política, pues reconoce que la calidad de la vida institucional está vinculada con la calidad de la vida personal.

Los NMS en un contexto de desafección política y cuestionamiento de la democracia liberal, centralizada y burocratizada, reivindican una legitimidad que no se fundamente solo en la democracia representativa y una mayor visibilidad de cómo se toman las decisiones sobre las políticas públicas. Los movimientos sociales han interiorizado el repertorio discursivo republicano y de 
esta forma cuestionan la burocracia, el centralismo, la delegación, la representación oligárquica (Manin, 1998), la partitocracia, la falta de transparencia y de acceso a la información y perseveran por implantar formas de democracia deliberativa que trasciendan el clivaje izquierda-derecha.

El intento de superar la escala izquierda-derecha también está presente en un tipo de pensamiento que se conoce como posmodernismo ${ }^{3}$ y que ha impactado en la política y en los NMS. Von Beyme (1994) señala que la cultura, el estilo de vida y la política se amalgamaron creando una interconexión de acción que nos llega hasta la actualidad. Los NMS, como paladines de la nueva política, rechazan la codificación tradicional de la política, las viejas categorías como izquierda-derecha, lo público-privado y lo político-apolítico. También desliga la política de las referencias institucionalizadas que le eran propias y el papel del liderazgo queda cuestionado. La movilización desde arriba se ve con cierto escepticismo y se prefiere formas movilizadoras de iniciativas particulares elegidas desde las bases. El pluralismo deviene en una visión que defiende la pluralidad de ideas, culturas, estilos de vida, objetivos y epistemologías.

Von Beyme (1994) establece que el postmodernismo no es tanto la sustitución del paradigma moderno por uno nuevo como su radicalización y culminación, lo que otorga a nuestra época una continuidad y solapamiento entre ambos.

El discurso posmoderno pone en el centro del debate la subjetividad como sustitutorio de los grandes relatos que suministraban las ideologías. De esta forma, lo transversal, lo próximo, lo inmediato, lo subjetivo se consagran como categorías reivindicativas de la política.

\section{La praxis reivindicativa de los indignados}

Tras esta aproximación realizada al fenómeno de los movimientos sociales que, sin ánimo de exhaustividad, ha pretendido esbozar algunos de sus rasgos más destacados y ha repasado algunas de las contribuciones del republicanismo contemporáneo al repertorio temático de los movimientos sociales desde un enfoque postmoderno, a continuación nos detendremos en un tipo de movimiento representativo de nuestra propuesta. El movimiento de indignados se presenta como un movimiento donde convergen numerosas reivindicaciones bajo diversos lemas políticos, en el que confluye una heterogeneidad de estrategias, de configuraciones organiza-

3 El pensamiento posmoderno se caracteriza por una enorme complejidad y no es una empresa fácil proporcionar una definición o introducción breve. Sintéticamente, y como aproximación conceptual, lo postmoderno se refiere a una época nueva que supera la modernidad, que genera nuevos productos culturales y que permite teorizar de una forma novedosa sobre nuestra realidad. Así, la teoría política moderna buscaba un fundamento universal y racional en sus análisis y explicaciones. Las teorías postmodernas rechazan el fundacionalismo y se orientan al relativismo, al nihilismo y rechazan la idea de un gran narrativa (Lyotard, 2006). De este modo, el término postmoderno deviene en una incredulidad en las metanarrativas. Con esto se aludía a las ideologías, consideradas como grandes narrativas. El filósofo francés celebraba la existencia de diversas perspectivas teóricas porque las ciencias sociales han entrado en una senda de variadas síntesis. El pensamiento postmoderno se identifica con el yo fragmentado, con la disolución del yo cartesiano. El sentimiento de vida postmoderno se vincula a la confusión de una vida compuesta de elementos contradictorios. Por otra parte, la postmodernidad ha de ser entendida y definida negativamente en referencia a su oposición y distanciamiento de la modernidad (Von Beyme, 1994). 
tivas, de formas de resistencia, etc., que se escapan a una rigurosa clasificación tipológica. Estas dificultades las podemos justificar mediante la sugerente metáfora de Dalton y Kuechler (1992, p. 37) cuando afirman que los movimientos sociales son como los tiburones: deben moverse constantemente para permanecer con vida.

Todos los movimientos sociales están directamente vinculados con su época histórica y esta afirmación facilita una interpretación más flexible para comprender el estallido de movilizaciones colectivas de indignados, en un contexto de crisis económica y financiera global, de reajustes constantes en el gasto público y de destrucción sistemática del empleo. La crisis económica no solo frenó la movilidad social de muchos ciudadanos, sino que los abismó a situaciones de precariedad y proporcionó la caja de resonancia favorable para el estallido colectivo.

El caso que se plantea, el del movimiento de indignados, encuentra eco a nivel mundial. Pero, como se ha afirmado anteriormente, cada contexto se define por sus propios matices y repertorios sustantivos y de acción. Todas las sociedades tienen cierto grado de insatisfacción y de descontento popular para generar un apoyo de minorías inconformes.

El calificativo de indignados hace referencia a un movimiento contestatario de protesta y resistencia que provoca la ruptura del miedo de los ciudadanos a protestar sobre los asuntos políticos, económicos y vitales que afectan a sus vidas. Las movilizaciones de los indignados se propusieron que la ciudadanía compartiera su modo de conceptualizar los problemas políticos y económicos.

El libro de Stéphane Hessel, Indignez-vous, había alentado la concienciación del deficiente funcionamiento del sistema hegemónico, de la dominación a la que están sometidos los jóvenes, sin futuro y sin esperanza. En el contexto español, el 15-M marcará el punto de inflexión del movimiento de indignados, que a través de plataformas como Democracia Real Ya y Afectados por la Hipoteca (PAH), Contra la Corrupción, Defensa de la Educación Pública, Derechos a saber, entre otras muchas, vehicularán las movilizaciones.

Una vez abierta la ventana de oportunidad para la emergencia de un movimiento de estas características, el discurso del 15-M4 incorporó algunas de las señas de identidad que hemos descrito de la tradición republicana. Esta ventana de oportunidad fue abierta por un contexto muy específico: la combinación de la crisis económica-financiera, cuyas secuelas persisten actualmente, la campaña electoral de las elecciones locales y autonómicas de 2011 y el recurso a las herramientas digitales que proporcionan las nuevas tecnologías. La organización más cambiante y laxa de estos movimientos sociales, además de su necesidad vital de "estar" en movimiento e innovar, ha hecho de la internet su herramienta fundamental y ha permitido el "ciberactivismo", entendido como el uso de las tecnologías de la comunicación que permiten comunicar y difundir a un gran público de forma instantánea (Castell, 2012).

$4 \quad$ El Movimiento 15-M, también llamado movimiento de los indignados se formó a raíz de la manifestación del 15 de mayo de 2011 en España. 
El movimiento del 15-M utilizó una heterogeneidad de lemas, frases y metáforas muy expresivas que cuestionaban la democracia representativa, la mercantilización de la vida, la precariedad laboral y la falta de horizontes vitales junto a una defensa de un sistema de corte asambleario, descentralizado, autónomo y desburocratizado.

La indignación popular consigue llamar la atención sobre la necesidad de defender lo público, de solidarizarse con los más desprotegidos, reivindicar una economía más justa, igualitaria y equitativa, exigir dispositivos de democracia directa y empoderar a la ciudadanía a no sucumbir al miedo a protestar. Todas estas reivindicaciones están pensadas desde la vía positiva, es decir, ideas de una realidad a construir, el ideal por realizar, una renovada aspiración del concepto de política que integre libertad, igualdad, derechos humanos, democracia, calidad en las políticas públicas y justicia.

Pero el movimiento de indignados también piensa y denuncia la política desde la vía negativa: donde, especulan sobre los obstáculos por superar, las deficiencias por eliminar y los males políticos que combatir. No se trata de construir un catálogo cerrado de todas las reivindicaciones de los indignados pero, entre las patologías del sistema que se denuncian, se recogen críticas a la corrupción sistémica, al cesarismo y decisionismo gubernamental, a la partitocracia, a la extrema delegación, a los medios de comunicación por su connivencia con las grandes corporaciones, la exigencia de control sobre las entidades bancarias, críticas a la endogamia institucional, a la ausencia de mérito en el reclutamiento para desempeñar cargos, al vaciamiento de la política, a la alienación del espacio público, a la colusión de intereses corporativos y políticos, a la captura del Estado, a la concentración de poder por parte de las cúpulas de los partidos políticos y los correspondientes déficits democráticos en su funcionamiento, junto a otras prolijas reivindicaciones. Asimismo, son exigencias de índole materialista, pero desde un enfoque posmaterialista, en un escenario de crisis económica vinculada a la redistribución y a la falta de horizontes en el futuro. De este modo, las reivindicaciones materiales como mantener los empleos, los salarios y las pensiones dignas, el derecho a la vivienda, frenar los desahucios, proteger los derechos laborales, la creación de empleo juvenil, mejorar la fiscalidad, eliminar los privilegios de los políticos y defender el Estado de Bienestar, se combinan con reivindicaciones postmaterialistas relacionadas con la democracia directa, la auto-organización social, la recuperación del espacio público, la toma de decisiones políticas transparentes, la descentralización, la dignidad, la calidad de vida y la defensa de lo público. Los valores posmaterialistas, en el sentido de Inglehart, propugnan un papel más activo del ciudadano coincidente con el ciudadano republicano.

Cheresky (2011) nos habla de democracia continua para explicar que las nuevas formas de acción colectiva son un síntoma de normalidad en la política contemporánea, una modalidad expresiva cotidiana para los ciudadanos en su permanente pronunciamiento. El sistema democrático representativo mantiene una tensión entre los principios democráticos y oligárquicos, con unos rasgos que le dan visibilidad como nunca antes había pasado y que el ciudadano contemporáneo considera que nadie puede representarlo mejor que él. En este sentido pue- 
de comprenderse que las movilizaciones ciudadanas son manifestaciones de autorrepresentación; el ciudadano solo quiere ser representado por sí mismo.

Un ciudadano empoderado consciente de su papel activo en el espacio público y vigilante sobre la actuación de los representantes políticos para cuestionar, expresar en voz alta, hacer visible y denunciar los casos en que los poderes públicos desvirtúan los objetivos generales.

\section{Consideraciones finales}

Los Nuevos Movimientos Sociales, tanto en América Latina como en Europa, generan numerosas demandas a través de formas de expresión política, alejadas de los modelos de hacer política tradicional y encuentran su materialización en un desdibujamiento del sistema político institucional como ámbito natural de la política. En las condiciones de la posmodernidad, la política se desparrama por la sociedad y el sistema político tradicional se ve transcendido en sus contornos. El estallido de lo local, la reivindicación de las identidades particulares discurre en paralelo con la pérdida de los grandes relatos legitimadores del Estado o críticos de la universalidad de la humanidad, como proclama el marxismo o el anarquismo (Simón, 2006 p. 75-77).

En este contexto donde se difuminan las grandes narraciones políticas, el discurso del republicanismo clásico, con sus temas de calado político como el autogobierno, la participación, la deliberación y el empoderamiento ciudadano unido a las virtudes cívicas y al rechazo a la corrupción, aparecen como una constante en el repertorio simbólico de los nuevos movimientos contemporáneos, suministrando sustantividad.

La visión posmoderna de la vida política implica, a su vez, la democratización de más espacios, la politización de ámbitos que, tradicionalmente, eran privados. Además, supone la entronización de la subjetividad, de la complejidad y de la transversalidad como categorías políticas unido a un enfoque crítico que cuestiona los modos políticos aceptados acríticamente y consagra la necesidad de la paradoja y de la contradicción.

A pesar de la fuerte presencia de los NMS en el espacio público, como afirma Von Beyme (1994, p. 276) parece que el compromiso político y la movilización necesitan casi más explicación que el desinterés político. Lo cierto es que en los movimientos sociales se produce una mezcla heterogénea de ideas modernas, posmodernas, republicanas y liberales y, como decíamos al inicio, en la teoría política raramente se considera que un paradigma está totalmente superado de una vez para siempre, la tendencia sugiere que todas estas ideas seguirán coexistiendo y combinándose en diferentes grados, según los condicionantes coyunturales y contextuales. 


\section{Referencias bibliográficas}

Abellán, M.A. (2014). Maquiavelo en la democracia republicana. Revista de Filosofía ARIEL, 14, pp. 33-38.

Abellán, M.A. (2014). Republicanismo contemporáneo y representación. Una ineludible convergencia. Política, vol. 52, 1, pp. 195-210.

Arendt, H. (1997). ¿Qué es la política? Barcelona: Paidós.

Castell, M. (2012). Redes de indignación y esperanza: los movimientos sociales en la era de Internet. Madrid: Alianza.

Cheresky, I. (comp). (2011). Ciudadanía y legitimidad democrática en América Latina. Buenos Aires: Prometeo.

Dalton, R.; Kuechler, \& Bürklin, M. (comp.) (1992). Los Nuevos Movimientos Sociales. Valencia: Edic. Alfons el Magnànim.

Della Porta, D. \& Diani, M. (2011). Los Movimientos Sociales. Madrid: Editorial Complutense. CIS.

Eder, K. (1998). La institucionalización de la acción colectiva ¿Hacia una nueva problemática teórica en el análisis de los movimientos sociales? en Tejerina, B. y lbarra, P. (eds) Los nuevos movimientos sociales: transformaciones políticas y cambio cultural. Madrid: Trotta.

Hessel, S. (2011). Indignez-vous! Paris: Indigène Editions.

Ibarra, P., Martí, S. \& Gomà, R. (coords.) (2002). Creadores de democracia radical. Movimientos sociales y redes de políticas públicas. Barcelona: Icaria.

Inglehart, R. (1991). El cambio cultural. Madrid: CIS.

Kaase, M. (1992). Movimientos sociales e innovación política en Dalton R. and Kuechler M. (comp.). Los Nuevos Movimientos Sociales. Valencia: Edic. Alfons el Magnànim.

Lyotard, J.F: (2006). La Condición Postmoderna. Madrid: Cátedra.

Manin, B. (1998). Los principios del gobierno representativo. Madrid: Alianza.

Pettit, P. (1999). Republicanismo. Una teoría sobre la libertad y el gobierno. Barcelona: Paidós. 
Pocock, J.G.A. (2002). El momento maquiavélico. El pensamiento florentino y la tradición republicana atlántica. Madrid: Tecnos.

Simón, M.A. (2006). “El pensamiento político postmoderno en América Latina”. Revista ÁMBITOS. 16: 73-84.

Skinner, Q. (2005). La libertad de las repúblicas: ¿un tercer concepto de libertad? Revista ISEGORIA. 33, pp.19-49.

Tarrow, S.G. (2012). El poder en movimiento. Los movimientos sociales, la acción colectiva y la política. Madrid: Alianza.

Viroli, M. (1997). Por amor a la patria. Madrid: Acento.

Von Beyme, K. (1994). Teoría política del siglo XX. De la modernidad a la postmodernidad. Madrid: Alianza.

\section{Recursos digitales}

Democracia Real Ya! (2011). "Propuestas de democracia Real Ya". Madrid: Democracia Real Ya! Consulta 15 de agosto 2014 (http://www.democraciarealya.es/documento-transversal/)

15-M. (2011). "La ideología del 15-M". Madrid: Movimiento Indignados Spanish Revolution. Consulta 15 de agosto 2014. (http://movimientoindignadosspanishrevolution.wordpress. com/ideologia-del-15m/)

Democracia participativa (2011). "Manifiesto por la democracia participativa". Granada: Democracia Participativa. Consulta 15 de agosto 2014. (http://www.democraciaparticipativa. es/index.php/manifiesto-por-la-democracia-participativa/) 